\title{
Analysis of Intensity in Different Light Cure Units Used in Dentistry
}

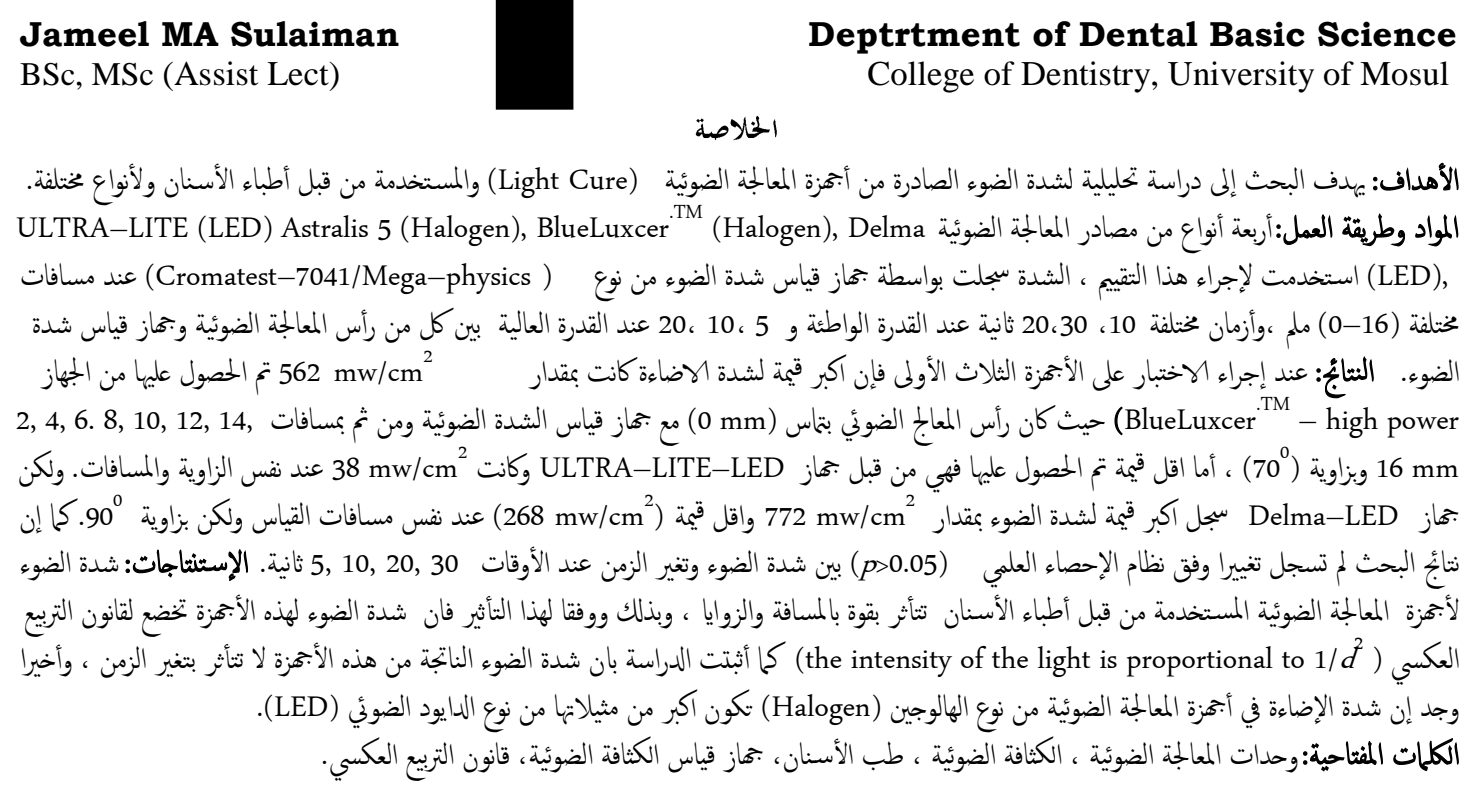

\begin{abstract}
Aims: The aim of this study was the analysis of intensity in different light cure units used in dentistry. Materials and Methods: Four types of light curing sources units; ULTRA-LITE (LED) Astralis 5 (Halogen), BlueLuxcer ${ }^{\mathrm{TM}}$ (Halogen), Delma (LED), were evaluated for the analysis. Light intensity was recorded at various distances of $0-16 \mathrm{~mm}$, between the light curing tip and a curing radiometer, and at different times (10, 20, 30 seconds) in low-power and at 5, 10, 20 seconds in high-power. Results: The highest light intensity for the first three types $\left(562 \mathrm{~mW} / \mathrm{cm}^{2}\right)$ was obtained by BlueLuxcer ${ }^{\mathrm{TM}}$ - high power when the tip of light curing unit was in contact with a curing radiometer. The light intensity for the three types of LCUs decreased significantly $(p<0.05)$ when the light tip was placed at an angle $70^{\circ}$ and distance $0,2,4,6,8,10,12,14,16 \mathrm{~mm}$ away from the a curing radiometer, and the lowest intensity $\left(38 \mathrm{~mW} / \mathrm{cm}^{2}\right)$ was obtained by ULTRA-LITE-LED. But the maximum light intensity for the light cure type Delma-LED, was $772 \mathrm{~mW} / \mathrm{cm}^{2}$ and the minimum was $268 \mathrm{~mW} / \mathrm{cm}^{2}$ when the light tip was placed perpendicular $90^{\circ}$ and distance $0,2,4,6,8,10,12,14,16 \mathrm{~mm}$ away from the a curing radiometer. Furthermore, no significant differences $(p>0.05)$ were detected between Intensity and varying time at 5, 10, 20, $30 \mathrm{sec}$. Conclusions: The intensity of the curing light was strongly affected by the angles and distance. The decrease in light intensity was significant $(p<0.05)$ when the light tip placed at an angle $70^{\circ}$ and a way to the aperture of the a curing radiometer, but the magnitude of the intensity it becomes more with the same procedure when the angle was perpendicular $90^{\circ}$. The decrease in the light intensity of the light curing units, agree with the inverse square law for the distances 0 to $16 \mathrm{~mm}$. The study found that there was no significant difference $(p>0.05)$ in light intensity between the light curing tip and a curing radiometer varying with time. This study notice that the intensity of the light cure type LED is less than QTH(Quartz Tungsten Halogen).

Keywords: Light cure units, Intensity, Dentistry, Curing radiometer, Inverse square law.
\end{abstract}

Sulaiman JMA. Analysis of Intensity in Different Light Cure Units Used in Dentistry. Al-Rafidain Dent J. 2010; 10(1): 192-197.

Received: $24 / 2 / 2010$

Sent to Referees: $28 / 2 / 2010$

Accepted for Publication: 4/4/2010

\section{INTRODUCTION}

Several studies presented applied application of the intensity in light cure which are widely used by dentists in his dental clinics. An increase in light intensity during polymerization has clearly an 
increase in temperature as a result ${ }^{(1)}$, with possible negative consequences of tooth health $^{(2)}$. It is important to increase the light curing time and use appropriate light curing devices to polymerize resin composite in deep cavities in order to maximize the hardness and compressive strength of restorative materials ${ }^{(3)}$.

The effect of light intensity found that when several samples were polymerized in low intensity $\left(390 \mathrm{mw} / \mathrm{cm}^{2}\right)$, they have a degree of conversion less than $10 \%$ with high residual monomer, and at $1 \mathrm{~mm}$ depth. The polyacid-modified composite resin is different in the degree of conversion and an amount of residual monomer at different intensities. As the light intensity increased, the degree of conversion measure is increased, while the residual monomer measure was decreased ${ }^{(4)}$. Polymerization of restorative material using high intensity polymerization devices will sufficiently harden resin, but will also lead to greater polymerization shrinkage and stress resulting in micro cracks as a consequence of shrinkage as well as greater increase in temperature that can compromise pulp vitality $^{(5)}$.

Recently, manufacturers have turned their attention to the light source used to convert composite materials from monomers to polymers ${ }^{(6)}$. Researchers have investigated the relationships among curing source intensity, exposure duration, and tip-to-tooth curing distance to achieve optimal resin cure ${ }^{(7)}$. Low light intensity and increased curing time can be used to cure composites with better performance than high intensity cured composites where the benefits of low intensity long time cure can be improve marginal integrity without loss of mechanical and physical properties $^{(8)}$.

It is considered that light intensity at a wave length of $470 \mathrm{~nm}$ may give a guide to polymerizing efficiency, since this is the peak absorption wave length for the catalyst system ${ }^{(9)}$.

The degree of polymerization also varies according to the distance from the surface of the composite to the light source.
Depth of cure decreases significantly as this distance increases. The potential of activation declines exponentially as a function of the distance from the surface of the filling ${ }^{(10)}$.

Dentists must be aware that highintensity LED curing lights may produce temperature increases that can damage pulp irreversibly. Given the various factors that affect the pulp during restorative treatments, an increase in temperature may contribute to irreversible damage. Based on the methodology used, the study shows that the temperature increase in dentin was directly proportional to the light intensity of the LED appliances. The high-intensity LED appliances produced significantly greater temperature increases in dentin than the QTH appliance, both during photo polymerization of resin composite and after 24 hours $^{(11)}$.

\section{MATERIALS AND METHODS}

Four types of Light Cure Source Units (LCUs) has been used in this study as shown in Table (1) and Figure (1). A Curing Radiometer, $(\lambda=400-500 \mathrm{~nm})$, CROMATEST (7041)/ Mega Physik, $\left(\mathrm{mw} / \mathrm{cm}^{2}\right)$, holder and (angle, meter) scale were used.

Method obtained the intensity $(\mathrm{mW}$ $/ \mathrm{cm}^{2}$ ) in different cases. In the first one, when the light tip was placed in contact $(0$ $\mathrm{mm}$ ) then at an angle $70^{\circ}$ and distance 2,4 , $6,8,10,12,14,16 \mathrm{~mm}$ away from the a curing radiometer for the first three types of light cure used. In the second case the tip light cure of type Delma - LED was placed perpendicular $90^{\circ}$ and the intensity was obtained by the same distance in above.In the third case, intensity was recorded in a different times, at 10, 20, 30 seconds in low-power, and 5, 10, 20 seconds in high-power, when the light tip was placed in contact $(0 \mathrm{~mm})$ then at an angle $70^{\circ}$ and distance $2,4,6,8,10,12$, $14,16 \mathrm{~mm}$ away from the a curing radiometer just by the light cure type BlueLuxcer ${ }^{\mathrm{TM}}$ because this device present the highest value of intensity in this test. 
Table (1): Technical details of the Light curing used in research.

\begin{tabular}{|c|c|c|c|c|c|}
\hline No. & $\begin{array}{l}\text { Light cure } \\
\text { code }\end{array}$ & Type & $\begin{array}{l}\text { Wavelength } \\
(\mathbf{n m})\end{array}$ & $\begin{array}{c}\text { Light } \\
\text { Intensity } \\
\mathrm{mW} / \mathrm{cm}^{2}\end{array}$ & Manufacture \\
\hline 1 & ULTRA-LITE & $\begin{array}{l}\text { LED, 200E, } \\
\text { Plus }\end{array}$ & $440-490$ & 800 & Taiwan \\
\hline 2 & $\begin{array}{c}\text { Astralis } 5- \\
\text { VIVADENT }\end{array}$ & $\begin{array}{c}\text { Conventional } \\
\text { QTH (Halo- } \\
\text { gen) }\end{array}$ & $410-490$ & 600 & Austria \\
\hline 3 & $\begin{array}{l}\text { BlueLuxcer }^{\mathrm{TM}} \\
\quad(\mathrm{M}-855) .\end{array}$ & $\begin{array}{c}\text { QTH } \\
\text { (Halogen } \\
\text { lamp) }\end{array}$ & $430-480$ & 1000 & Taiwan \\
\hline 4 & Delma & LED & $420-480$ & $>1200$ & China \\
\hline
\end{tabular}

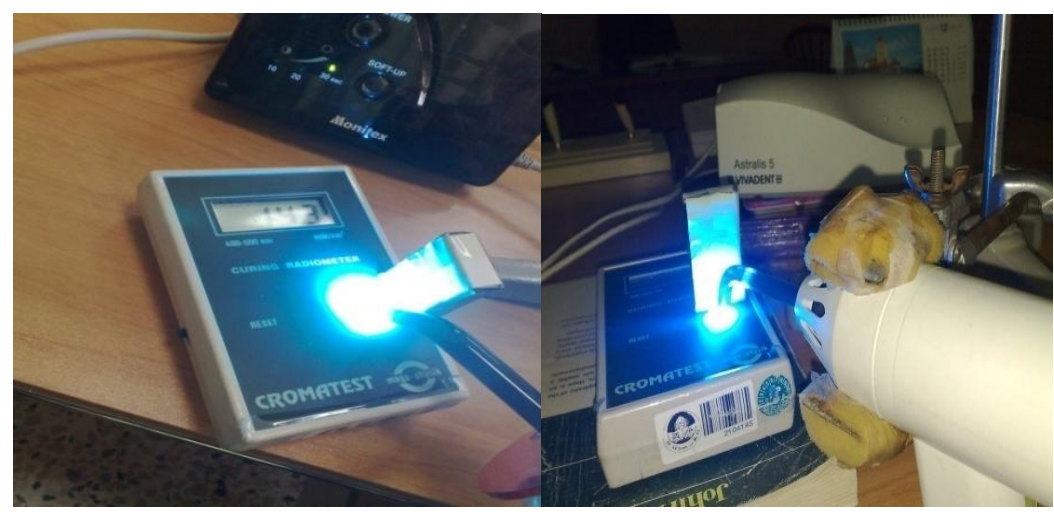

Figure (1): Light cure [BlueLuxcer ${ }^{\mathrm{TM}}(\mathrm{M}-855)$ and Astralis 5-VIVADENT ] testing by a curing radiometer CROMATEST (7041).

\section{RESULTS}

The intensity of the first three types LCUs is recorded when the light tip was placed in contact $(0 \mathrm{~mm})$ then an angle $70^{\circ}$ and distance 2, 4, 6, 8, 10, 12, 14, $16 \mathrm{~mm}$ away from the a curing radiometer, the highest light intensity $\left(562 \mathrm{~mW} / \mathrm{cm}^{2}\right)$ was obtained by BlueLuxcer $^{\mathrm{TM}}$ (M-855, Halogen lamp - high power).

The light intensity decreased to 38 $\mathrm{mW} / \mathrm{cm}^{2}$ for ULTRA-LITE (LED type, $200 \mathrm{E}$, Plus) significantly ( $p=0.026)$. Statistical analysis was performed using $\mathrm{Chi}-$ Square test, (Figure 2).

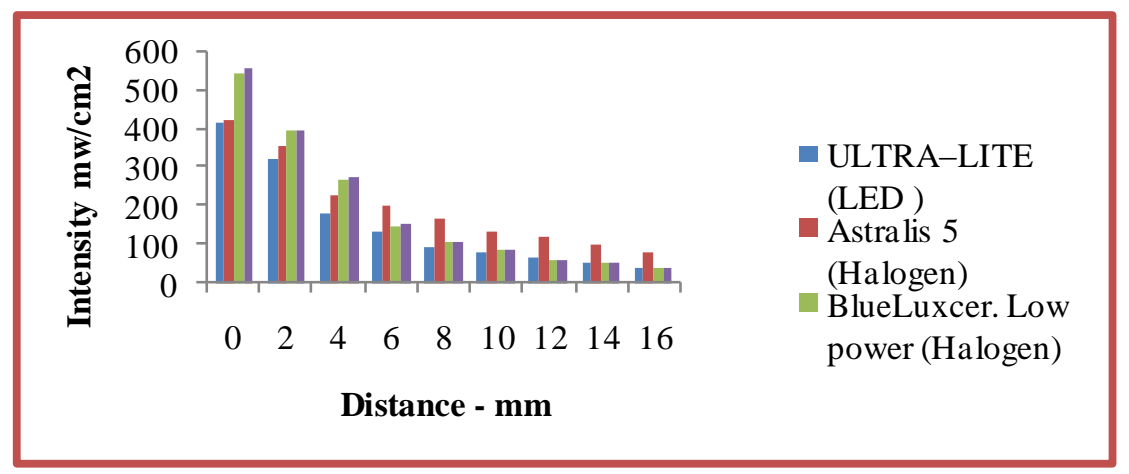

Figure (2): The intensity of three type LCUs is a variable with distance, at angle $70^{\circ}$. 
But the maximum light intensity for the light cure type Delma-LED, was $772 \mathrm{~mW} / \mathrm{cm}^{2}$ and the minimum was $268 \mathrm{~mW} / \mathrm{cm}^{2}$. When the light tip was placed perpendicular $90^{\circ}$ and distance $0,2,4,6,8,10,12,14,16 \mathrm{~mm}$ away from the a curing radiometer (Figure 3). Furthermore, no significant differences $(p=0.527)$ were detected between intensity and varying times at $5,10,20,30 \mathrm{sec}$ and any distance 0,2 , $4,6,8,10,12,14,16 \mathrm{~mm}$ to be fixed at each of the value of the changing time, (Figure 4). Another result have been notice in this study, the intensity of the light cure type LED is less than light cure type QTH(Quartz Tungsten Halogen).

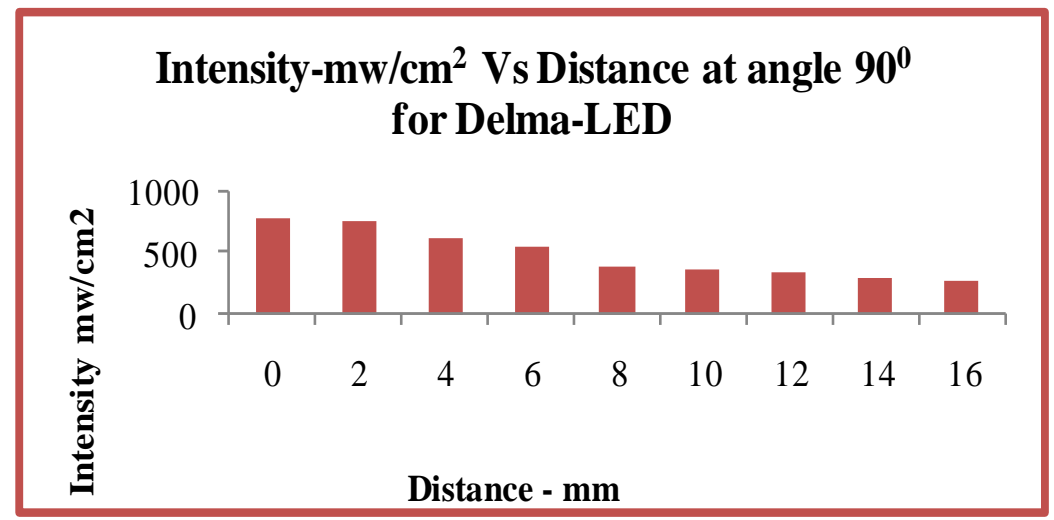

Figure (3): The intensity of Delma - LED is a variable with distance, at angle $90^{\circ}$.

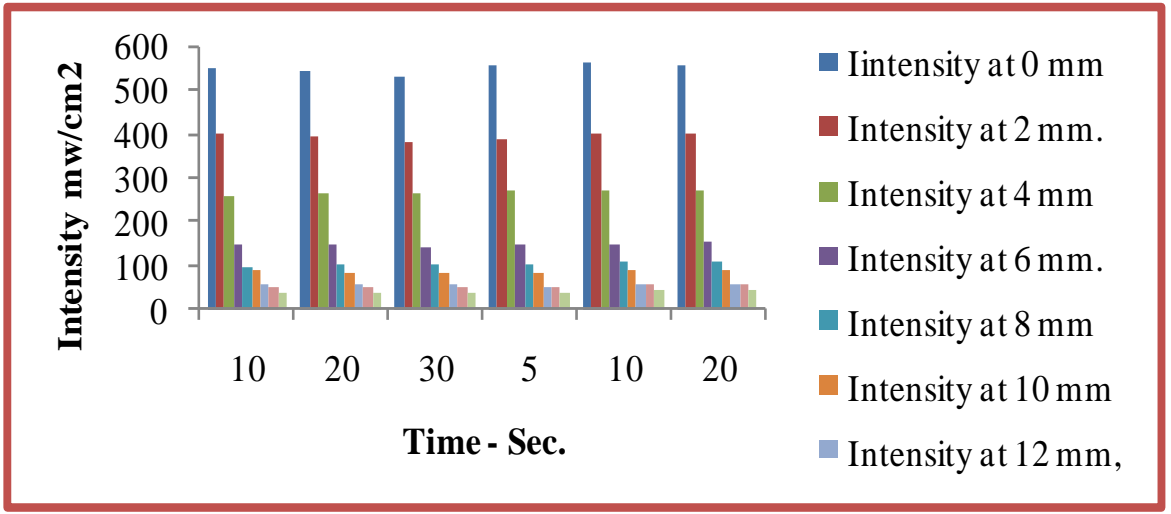

Figure (4): Intensity varying time.

\section{DISCUSSION}

The analysis of intensity in different light cure units sources used in dentistry presented four main results as follow:

1. The intensity $\left(\mathrm{mW} / \mathrm{cm}^{2)}\right.$ was significantly $(p=0.026)$ and strongly affected by distance and angles when the light cure tip was placed in contact $(0 \mathrm{~mm})$ then at an angle $70^{\circ}$ and perpendicular $90^{\circ}$ respectively with a distance $2,4,6,8,10,12,14,16 \mathrm{~mm}$ away from the a curing radiometer (Figures 2 and 3).

2. Varying time was not depended in the intensity, for example the intensity was 402, 399, 388, 392, 402, 404 $\mathrm{mW} / \mathrm{cm}^{2}$ at the time $10,20,30,5$, $10,20 \mathrm{sec}$ respectively and at fixed distance $(2 \mathrm{~mm})$, and this result appears that there were no significant differences ( $p=0.527)$, (Figure 4$)$.

3 . The intensity of light cure source type LED is less than Halogen, and this 
clearly sign in (Figure 2).

4. The decrease in light intensity of the light curing units, agreed with the inverse square law for the distances 0 to $16 \mathrm{~mm}$ (Figure 5). As a point light source moved away, the intensity of the light is proportional to $1 / d^{2}$, the inverse square of the distance, this is what is meant by the "Inverse Square Law". Because the same geometry applies to many physical phenomena (sound, gravity, electrostatic interactions), the inverse square law has significance to many problems in physics. Now imagine (Figure 6), the light that falls in a square at some arbitrary distance from the star $(d=1$, yellow square). Move away, doubling the distance from the star $(d=2)$. The light from the original square has now "spread out" over an area of $4\left(=2^{2}\right)$ squares. Thus, at twice the original distance, the intensity of the light passing through a single square will be $1 / 4$ of the original intensity. Going out still further, tripling the original distance $(d$ $=3$ ), and the light from the original square now covers an area of $9\left(=3^{2}\right)$ squares $^{(12)}$.

The intensity of the light $I_{x}$ at a distance $x$ from the surface is given by the function: $I_{x}=I_{0}{ }^{-\mu x}$

Where $1_{0}$ is the light intensity at the surface and $\mu$ is the absorption coefficient of the material. Since a certain level of intensity is required to cause activation it follows that light activated materials have a limited depth of cure ${ }^{(13)}$.

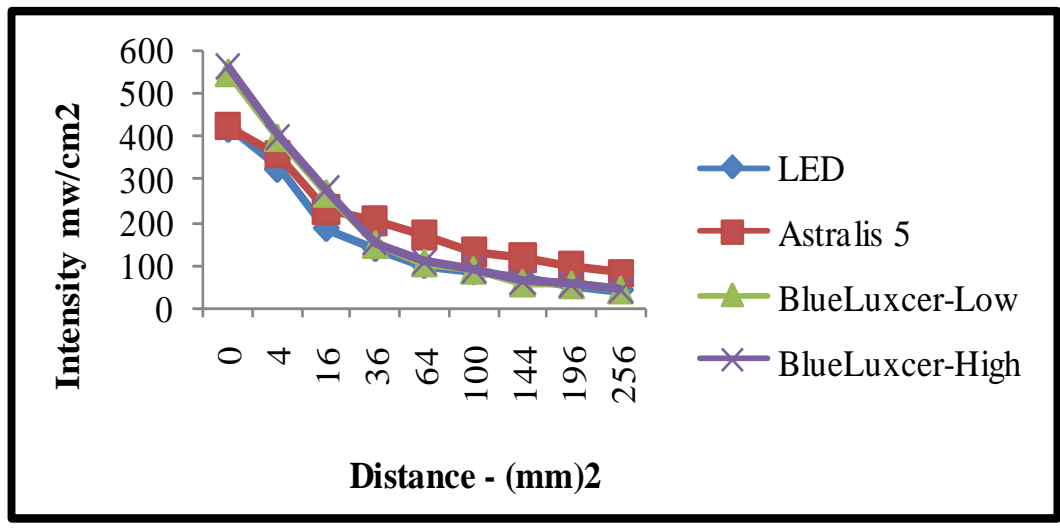

Figure (5): The decrease in light intensity of the light curing unit was agree with the inverse square law.

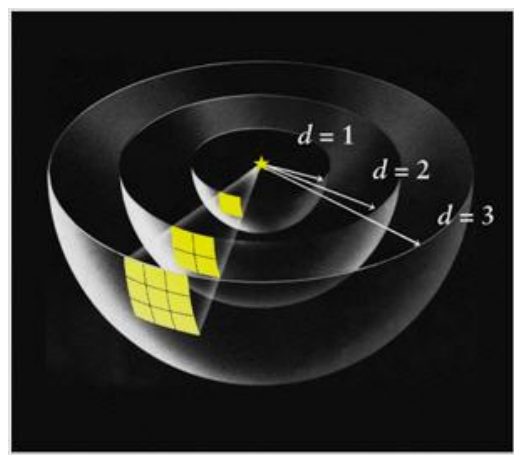

Figure (6): The light is proportional to $1 / \mathrm{d}^{2}$, the inverse square of the distance. 


\section{CONCLUSIONS}

The intensity of the curing light was strongly affected by the angle and distance. The decrease in light intensity was significant $(p<0.05)$ when the light tip placed at an angle $70^{\circ}$ and a way to the aperture of the a curing radiometer, but the magnitude of the intensity it becomes more with the same procedure when the angle was perpendicular $90^{\circ}$. The decrease in light intensity of the light curing units, agreed with the inverse square law for the distances 0 to $16 \mathrm{~mm}$. The study found that there was no significant difference ( $p>0.05$ ) in light intensity between the light curing tip and a curing radiometer varying with time. Also, this study noticed that the intensity of the light cure type LED is less than QTH (Quartz Tungsten Halogen).

\section{REFERENCES}

1. Hannig M, Bott B. In-vitro pulp Chamber temperature rise during composite resin polymerization with various light curing sources. Dent Mater. 1999; 15: 275-281.

2. Nicoleta I, Kathrin F, Katja T, Reinhard H, Karl-Heinz K. Shrinkage behavior of a resin-based composite irradiated with modern curing units. Dent mater. 2005; 21(5): 483-489.

3. Riza Alpöz A, Ertuğrul F, Cogulu D, Akc AT, Tanoğlu M, Kaya E. Effects of light curing method and exposure time on mechanical properties of resin based dental materials. Europ $J$ Dent. 2008; 2(Jan).

4. Al-Jadwaa FT. The effect of curing time and light intensity on the degree of conversion of poly-acid modified composite resin. Msc Thesis. College of Dentistry, University of Mosul. 2008.
5. Knežević A, Tarle Z, Ristic M, Alajbeg I. Influence of polymerization light intensity on the degree of conversion of composite materials (Part I). Acta Stomatol Croat. 2005; 39(4).

6. Emami N, Soderholm K-JM, Berglund LA. Effect of light power density variations on bulk curing properties of dental composites. J Dent. 2003; 31: 189-196.

7. Dlugokiniski MD, Caughman WF, Rueggeberg FA. Assessing the effect of extraneous light on photo activated resin composites. J Am Dent Assoc. 1998; 129: 1103.

8. Emani-Alagha, Nazanin. Effect of light power density variation on dental light-cure resin composites. Licentiate Thesis. Lulea University of Technology. 2001.

9. Mc Cabe JF, Carrick TE. Output from visible-light activation units and depth of cure of light-activated composites. J Dent Res. 1989; 68: 1534.

10. McCabe JF, Walls AWG. Applied Dental. $8^{\text {th }}$ Edition. Black well Publishing. 1998.

11. Mollica FB, Silva MA, Maximo De Araujo MA, Lima Huhtala MFR, Balducci I. Temperature variation caused by high-intensity LED curing lights in bovine dentin. Gener Dent. 2009; 57 (2): $342-347$.

12. Joly Photometer. School of Education. University of Queensland, Brisbane, Australia. 2006.

13. Radzi Z, Abu Kasim NH, Yahya NA, Abo Osman, Kassim NL. Relationship of the light intensity of selected light curing units with varying distance and angulations of the light curing tip and light meter. Annal Dent Univ Malaya. 2008; 15(1): 33-39. 